\title{
Revisitando a problemática teórico-prática do Estado: contribuição ao estudo do Estado para o Serviço Social.
}

Revisiting the theoretical-practical problematic of the State: contribution to the study of the State for Social Work.

Renato Francisco dos Santos Paula*

\begin{abstract}
Resumo
O presente artigo busca de modo sumário apresentar um esboço teórico-metodológico da evolução do pensamento sobre o Estado no amplo campo das Ciências Sociais, dos clássicos aos contemporâneos. Apresenta o modo como o Estado se tornou o eixo central das análises sobre o poder, sendo ele mesmo uma instância de exercício do poder. Destaca a sua natureza relacional e as inflexões que sofre decorrentes da luta de classes.
\end{abstract}

Palavras-Chave: Estado. Teoria social. Ciência política. Luta de classes. História.

\begin{abstract}
The present article seeks in a summary way to present a theoretical-methodological outline of the evolution of the thought about the State in the broad field of social sciences, from the classics to the contemporaries. It presents the way in which the state has become the central axis of the analyze of power, being itself an instance of the exercise of power. It emphasizes its relational nature and inflections that it suffers from the class struggle.
\end{abstract}

Keywords: State. Social theory. Political science. Class struggle. History.

\section{Introdução}

O convite generoso dos editores do periódico Serviço Social em Revista da Universidade Estadual de Londrina (UEL) para compartilhar parte de nossos estudos na edição comemorativa dos 20 anos da Revista é ao mesmo tempo uma honra e um desafio. Nos sentimos honrados em fazer parte do seleto grupo de autores aqui presente e ao mesmo tempo nos sentimos desafiados a apresentar uma contribuição reflexiva relevante para os leitores da Revista, justamente, em tempos onde o conhecimento científico tem sido duramente atacado pela razão instrumental exacerbada e sustentada em posicionamentos autocráticos de cariz fascista que se colocam claramente contrários à critica e ao livre pensamento.

\footnotetext{
* Doutor em Serviço Social pela PUC-SP, Docente na Universidade Federal de Goiás (UFG). E-mail: renato.paula@gmail.com
} 
Pensando nesse desafio, escolheu-se aqui, exercendo a liberdade que foi dada pelos editores, compartilhar alguns elementos conceituais e históricos de nossos estudos sobre a problemática teórico-prática do Estado, estudos que a propósito do debate sobre o “neodesenvolvimentismo" no Brasil, temos desenvolvido já há uma década¹.

Entende-se que o Estado é um objeto de estudo de acesso complexo, pois sua forma e conteúdo se forjam a partir de um número incontável de mediações. Por isso mesmo, ao estudar o Estado depara-se com formulações diversas, mas que refletem, em última instância, os interesses de quem formula a análise. Isso faz do Estado, um ente em disputa. Disputa hegemonizada pela classe dominante cuja, manutenção de seu poder depende quase que exclusivamente da ação do Estado. Portanto, pensar no avanço para outro tipo de sociedade que não seja a sociedade dominada pelo modo de produção capitalista, implica em compreender algumas premissas fundamentais sobre o Estado burguês:

1. O Estado é um ente social e historicamente determinado, de natureza fundamentalmente relacional;

2. Sua existência está condicionada ao uso da razão. Isto é, só existe no âmbito do projeto da racionalidade humana, em sua dimensão política. Fora disso, não se realiza, é etéreo e amorfo;

3. Só pode ser entendido se referenciado a uma formação social específica. Isto é, adquire a identidade da sociedade em que se insere. Identidade esta, vinculada ao modo como se estabelecem as relações sociais - consequência direta dos processos de produção e reprodução da vida social - e a maneira como as disputas de poder são travadas nessas relações;

4. Portanto, sua existência não pode ser desvinculada do surgimento das classes, nem da dinâmica que estabelecem entre si e suas frações;

5. Por ser relacional, não há consenso sobre apresentar autonomia, ainda que relativa, ante a dinâmica das classes sociais;

6. Além de ser revestido ideologicamente pelo formato que assume, oscila entre papéis protagônicos ou marginais, no processo de criação e difusão da ideologia dominante, sem abrir mão desse papel em nenhuma condição histórica;

\footnotetext{
${ }^{1} \mathrm{O}$ aprofundamento das questões aqui levantadas pode ser conferido em: (PAULA, 2016).
} 
7. Sua participação nos processos de reprodução das relações sociais é, em algumas análises, orientada pela classe dominante; em outras, é a própria classe dominante plasmada em sua forma. Alterna, assim, intervenções ora drásticas, ora moderadas, na vida socioeconômica, sempre com o fim último de manter os níveis exponenciais de expansão e acumulação capitalistas;

8. O monopólio legal da violência é uma característica própria intransponível, razão da sua autojustificação;

9. O caráter contraditório de sua existência reflete-se, dentre outras formas, no fato de possuir intrinsecamente as condições para sua manutenção perpetuadora como também de sua superação, para alguns, e extinção, para outros. Contradição essencial do sistema do capital incorporada pelo Estado burguês ou inexorável a ele. Portanto, desse modo, é indispensável para a transição socialista. Não há, por outro lado, consenso sobre as formas de encaminhamento dessa transição, gerando as mais profícuas polêmicas no campo da tradição marxista.

10. Acompanhando a evolução humano-social, os Estados migraram de simples organizações locais para conglomerados complexos mundializados. Portanto, suas formas contemporâneas não conseguem abdicar das relações imbricadas que se estabelecem na aldeia global.

Essas características mostram a heterogeneidade interna (e externa, por ter condicionantes materiais - históricos e sociais - claros) da problemática teórico-prática do Estado.

Diante de tamanha diversidade conceitual, cumpre-nos, explicitar que não entendemos o Estado como uma hipostasia da superestrutura, ou como um ente aprisionado no âmbito superestrutural, que sobrevive à espera das ordens burguesas voltadas à satisfação de seus interesses de acumulação crescente. Nem mesmo consideramos o estudo da problemática teórico-prática do Estado como circunscrito ao método. O tratamento que dispensamos ao Estado, nas pistas de Codato (2008) procura associar três modos distintos e relacionáveis de conhecimento: o conhecimento filosófico sobre ele construído, contido nos clássicos do marxismo; a justaposição entre teoria marxista e teoria socialista, portanto, o conhecimento político próprio das esquerdas marxistas; e o conhecimento científico "exigido para conquistar o objeto de pesquisa (O Estado capitalista) das sociologias não marxistas" (CODATO, 2008, p.84-85). Nesse entendimento, a concepção de Estado capitalista não se dissocia da dinâmica da transição 
socialista, pois não há como ignorar a existência do Estado no processo de constituição de uma sociedade que, ao mesmo tempo em que avança em conquistas civilizatórias - todas elas referidas ao avanço das forças produtivas -, generaliza a expropriação do trabalho e repõe, no mesmo processo, fissuras que permitem a sua superação.

Portanto, o Estado plasma-se no processo de lutas que friccionam a relação orgânica e dialética entre estrutura e superestrutura, como mediação de interesses econômicos, políticos, ideológicos, culturais, consequentes e que, em última instância, podem ser direcionados para a conquista da emancipação humana. O erro comum consiste em considerar que o tratamento do Estado como relação abrange concessões reformistas e mistificadoras à ordem do capital. Ao contrário, tal tratamento nos permite, pois, percorrer trajeto analítico similar ao de Marx, quando desvendou o mito da mercadoria e, nesses aprofundamentos, nos ensinou que o Capital é antes de mais nada uma relação social. Desse modo, o poder do Estado, por analogia, é "visto como uma forma-política determinada (isto é, 'condensada') pelas relações de força - instáveis, cambiáveis, provisórias - entre as classes implicadas nas lutas políticas" (CODATO, 2008, p. 83).

Essa concepção de Estado, aqui muito brevemente sumarizada, tem sido trabalhada e aprofundada por nós em outros trabalhos, todavia, sintetiza-la aqui tem o objetivo de explicitar que as seções que se seguem nesse artigo trazem apenas os elementos conceituais e históricos que permitirão chegar a esse conjunto de conclusões. Deste modo, o leitor não irá encontrar a análise aprofundada dos componentes axiais que entende-se conformar e formar o Estado, mas sim o modo como este foi se tornando o elemento constitutivo de um vasto campo científico.

\section{O estado no contexto da ciência ao longo da história}

A preocupação dos seres humanos em explicar os fatos e fenômenos que circundam a sua vida é tão antiga quanto sua própria existência. Nessa preocupação reside a origem de descobertas científicas fundamentais ao processo civilizatório de nossa espécie. Após séculos de explicações atribuídas a vontades sobrenaturais, a humanidade indaga sobre a necessidade de encontrar respostas nas coisas, nelas mesmas, e vê no homem o agente nuclear de seu próprio destino. Nos enciclopedistas franceses, na Astronomia e Física, com Pascal e Newton; na Química, com Lavoisier; na Matemática, com Descartes; na Medicina e Biologia, de Hipócrates a Darwin; nas Artes, na Cultura, Literatura, nas 
Engenharias e em todos os objetos cognoscíveis em relação aos seres cognoscentes, o homem e a sua razão ocupam o leit motiv desses campos do conhecimento, ao mesmo passo em que promovem a ruptura com as explicações teocêntricas no período ilustrado².

Mas, a construção da racionalidade humana não se limita a esses campos de conhecimento destacados. Desenvolve-se, pari passu, uma razão que busca desvendar as dinâmicas, das mais simples às mais complexas, da sociedade humana; suas formas de organização, seus sentidos, sua razão histórica. Assim, desenvolvem-se campos do conhecimento que vão desde os sentidos e a razão da política, por exemplo, entendida em Aristóteles como o caminho para se alcançar a felicidade humana, até as diversas formas de se viver na polis como os diferentes regimes e instituições políticas, passando evidentemente pela construção do direito positivo, dos contratos sociais, dos ciclos de desenvolvimento das sociedades emergentes de mercado, e das sociedades que podem ser construídas depois de atestadas determinadas condições da evolução humana, como o socialismo ou o comunismo.

A expansão desse leque de possibilidades de conhecimento e inerente prática sociopolítica funda, como necessidade de sua própria justificativa, disciplinas que se dedicam a esmiuçar as particularidades de um objeto de investigação, que sempre em processo de franca expansão se desdobrará em ininterruptos conjuntos de novos objetos: a Política. É assim que nasce a filosofia política, a ciência política, a sociologia política e a sociologia da política, cujas distinções entre elas não subtraem o fulcro comum existente nas relações humanas de conjunto.

A raiz comum dessas ciências está na necessidade imperativa de construir, pela razão lógico-abstrata ou empírica, explicações, precedidas de métodos, para as questões afetas ao poder e ao Estado. Estes são tomados como variáveis interdependentes e a categoria política que os une adquire ênfase diferenciada, a depender dos motivos que suscitam sua análise, do método ao resultado.

A Filosofia Política, por exemplo, sendo filosofia, utiliza como recurso metodológico o raciocínio lógico dedutivo, e tem, assim, um caráter normativo. Está, portanto, na raiz dos conhecimentos científicos, em especial do campo denominado de Humanidades. Aristóteles afirma que a Filosofia estuda os princípios originários de todas as coisas e o "Ser enquanto

\footnotetext{
${ }^{2} \mathrm{O}$ período a que nos referimos compreende boa parte do século XVIII. Nele, intelectuais europeus, sobretudo franceses, argumentam sobre a supremacia da razão humana opondo-se frontalmente à lógica teocrática e teocêntrica e ao absolutismo monárquico.
} 
Ser", ou seja, as essências. Adjetivada com a política, a filosofia tende a indagar a essência lógica e racional do poder. Filósofos políticos como os ingleses Thomas Hobbes (1588-1679) ou John Locke (1632-1704), e o suíço Jean Jacques Rousseau (1712-1778) se ocuparam em pensar como as relações de poder podem ser estabelecidas de modo a atender às necessidades de sobrevivência dos homens, quando estes transcendem de seu estado primitivo para a condição de seres que sobrevivem em sociedade, e, nesse salto, legitimam um poder superior que garanta essa coexistência. A partir de uma construção lógico-abstrata inferem sobre a origem do Estado e da Sociedade e atribuem a entificação do primeiro à sobrevivência do segundo. Pensavam num Estado ideal.

\begin{abstract}
A contribuição da Filosofia Política apresenta-se, ainda, na sua preocupação em caracterizar com precisão o "fenômeno político", ou seja, estabelecer com rigor lógico a especificidade dos fatos políticos em relação a outros tipos de acontecimentos. Ao distinguir, por exemplo, o campo político do mundo da moralidade privada, a Filosofia Política contribui com a autonomização do saber político. A Filosofia Política, então, dá os parâmetros para a construção do saber científico tanto da Ciência Política quanto da Sociologia Política, mas não se confunde com elas. (SOUZA, 2008, p. 9).
\end{abstract}

O raciocínio dedutivo que a caracteriza funda tanto a lógica como sua ciência quanto às teorias do conhecimento. Encontramos, por exemplo, no Ensaio sobre o Entendimento Humano, de John Locke, as premissas para "a análise de cada uma das formas de conhecimento que possuímos, a origem de nossas ideias e nossos discursos, a finalidade das teorias e as capacidades do sujeito cognoscente relacionadas com os objetos que ele pode conhecer" (CHAUÍ, 2010, p. 167).

A Ciência Política, por seu turno, sustenta-se na empiria. O método é o indutivo, diferente da dedução que se pratica na Filosofia, embora isso não seja suficiente para explicar as diferenças fundamentais entre os saberes de um ou outro campo, considerandose, ainda, que tal distinção só é possível no sentido stricto, pois, num sentido amplo e não técnico, o termo ciência política pode se referir ao estudo de qualquer fenômeno ou estrutura afetos ao campo da política desde que especializado. Bobbio (2007, p. 164) não só confirma tal assertiva quanto anuncia que a preocupação principal da Filosofia Política é com aquilo que deveria ou poderia vir a ser, enquanto a Ciência Política contém pressupostos de operatividade, ainda que isso não signifique que "os ideais tenham sido na história das mudanças políticas menos 'operativos' do que os conselhos dos 'engenheiros sociais'". 
O centro das preocupações permanece nas relações de poder, embora a ênfase da Ciência recaia um pouco mais sobre as instituições e nos regimes que as orientam. A instalação dos regimes políticos ajuda a conformar o desenho dos Estados, e, com isso, se conformam também as instituições estatais ${ }^{3}$. Nelas se materializa a sua estrutura jurídicopolítica, alvo das problematizações pioneiras da Ciência Política4.

Assim, notamos que a Ciência Política se debruça sobre as particularidades da relação poder-Estado-sociedade tratando, além dos regimes políticos, como já mencionado, dos problemas afetos às eleições, do poder, da autoridade, administração pública, das relações exteriores, dos partidos, dentre outros. Conceitos estes entrecortados por categorias sociológicas que os sustentam e/ou os contextualizam como: classes sociais, ideologia, status etc., próprios da Sociologia, e requisitados como recurso interdisciplinar. Mas como disciplina, a Sociologia Política se calça, sobretudo, nas relações sociais decorrentes do modo como os indivíduos se organizam no processo de produção e reprodução social da vida, criando sempre, na correlação de forças, mecanismos civilizatórios de participação no "mundo dos homens". Antônio Gramsci (1891-1937) ao estabelecer o esquema dialético de distinção entre sociedade política e sociedade civil $^{5}$ possibilita a compreensão do modo pelo qual a sociologia política pode se ocupar em estudar as maneiras como a sociedade influencia a arena pública, exerce o poder, disputa e conquista hegemonia na esfera estatal.

Antes dele, Hegel (1770-1831), e outros, da escola idealista alemã, enalteceram a atividade livre e racional e se ocuparam em pensar "o eu" e "o todo" como forma de

\footnotetext{
${ }^{3}$ Claro que não é uma afirmação linear. A opção pelos regimes políticos é uma construção histórica decorrente da confluência de inúmeras variáveis, que dão sentido ao Estado, mas a luta por um regime específico também pode ser o fator decisivo na inauguração de um tipo de Estado qualquer.

${ }^{4}$ Por isso que o modo como as considerações sobre o poder, feitas por Maquiavel (Niccolò Machiavelli, 14691527) em $O$ Príncipe, são consideradas como notas postulares, que dão origem ao Estado moderno, mesmo nas conjunturas absolutistas. Do mesmo modo, Montesquieu (1689 - 1755) quando propõe a constituição tripartite dos poderes do Estado: Judiciário, Legislativo e Executivo, mesmo em outra época, rende-se a pensar também "relações de poder". São dois exemplos, por serem "incomuns" que nos mostram como as questões da estrutura estatal ocuparam tanto filósofos quanto cientistas políticos, fazendo com que a interdependência entre os saberes se estabeleça como um imperativo para a definição de um campo de conhecimento científico que tem por objeto um ente relacional, sendo um conhecimento mais dinâmico e não rígido como se define nas ciências naturais.

${ }^{5}$ Gramsci estabelece uma distinção dialética entre estes dois segmentos: a Sociedade política, que compreende os aparelhos de coerção sob o controle das burocracias executivas e do aparato jurídico-militar, e Sociedade civil, que abarca o conjunto de organizações responsáveis pela difusão das ideologias que sustentam o consenso (hegemonia) no Estado burguês, ainda que dentre esses "aparelhos" possam existir aqueles que se colocam contrários à lógica dominante. Esses organismos vão desde o partido político e organizações sindicais até os veículos de comunicação, Igreja, Escola etc.
} 
projetar um Estado ético e de liberdade em suas práticas políticas ${ }^{6}$. Isto porque a disciplina sugere a articulação dialética entre Sociologia e Política, a primeira tratando dos problemas da sociedade humana ancorada por teorias sociais amplas e a segunda tratando dos meios e processos civilizatórios que circundam a organização da sociedade e as formas para se resolver os problemas elencados pela primeira.

Esse conhecimento pode, ainda, ser adjetivado, quando reduzimos seu escopo de atuação em Sociologia da Política. Aqui, não se trata de nenhum campo autônomo das ciências sociais, apenas da definição com precisão, por meio de um anúncio prévio do recorte epistemológico abordado. Equivale a outras adjetivações da Sociologia, como sociologia da educação, sociologia do trabalho, sociologia da administração, sociologia da religião, sociologia da cultura etc.

Em síntese, as motivações que induzem os seres humanos a pensar e a fazer Política, de sua essência à técnica, não prescindem da interdependência de categorias como o Estado e o poder, portanto, cumpre-nos considerar que o Estado, nas ciências sociais, é um dos objetos que, ao lado de outros, como o poder e a sociedade, como já dissemos, legitima a racionalidade das teorias do conhecimento e funda as principais ciências que se ocupam da política, no âmbito do advento da modernidade.

É quase consenso, no campo das ciências, que esses elementos interdependentes, em especial o Estado, sejam considerados seus objetos estruturantes. Contudo, ao longo do processo que os torna elementos constitutivos imprescindíveis para a formulação de um pensamento crítico, em especial no bojo da tradição marxista, é possível notar que nem sempre seus componentes axiais econômicos e políticos estão presentes de modo decisivo na orientação das análises.

\section{O Desterro e o Retorno Triunfal do Estado}

Perry Anderson e Atílio Borón, por caminhos distintos, submeteram esse processo à crítica, e, no final, convergem, ao demonstrar que a construção ontológica dessas categorias deve permitir plasmar-se no movimento dialético próprio da realidade em que se assenta, recusando a linearidade e a construção da crítica (que articula teoria e prática política) entendida apenas como uma sucessão evolutiva natural de fatos, acontecimentos e

\footnotetext{
${ }^{6}$ Neste sentido consultar: (MARCUSE, 2004).
} 
vontades pessoais de seus protagonistas. Ambos chamam a atenção para a centralidade da luta de classes como mola propulsora e estruturante das ciências sociais, que buscam lastro no Estado e em suas dinâmicas econômicas, políticas, ideológicas etc., inerentes, no âmbito da tradição marxista. Inferem que sua ausência pode conduzir a um academicismo distante da prática revolucionária concreta (Anderson) quanto à legitimação da ordem burguesa e do pensamento conservador (Borón).

O historiador inglês faz referência ao movimento descontínuo do tratamento dessas categorias no marxismo ocidental (eurocentrado) e o sociólogo argentino relembra do resgate da problemática do Estado no contexto latino-americano, nas últimas quadras do século XX, após um longo período de marginalização nos círculos político e acadêmico.

Anderson (2004) refere que o marxismo ocidental foi acometido de um silêncio sobre as estruturas econômicas e políticas como objetos centrais da teoria, causado por um deslocamento para a filosofia:

\begin{abstract}
O deslocamento básico de todo o eixo gravitacional do marxismo europeu no sentido da filosofia foi resultado do abandono progressivo de estruturas econômicas ou políticas como objetos centrais da teoria. [...] Os determinantes externos que levaram à substituição da economia e da política pela filosofia como foco principal da teoria marxista e das assembleias partidárias pelos departamentos acadêmicos como seus centros formais estavam inscritos na sombria história do período [...] [Mas] o evento decisivo para tal transformação foi a tardia descoberta do mais importante trabalho do jovem Marx - os Manuscritos de Paris de 1844, que foram publicados pela primeira vez em Moscou, em 1932 (ANDERSON, 2004, p. 69-70) ${ }^{7}$.
\end{abstract}

Refere, o historiador inglês, que ainda que os impactos dessa descoberta tenham sido abafados pela vitória do nazismo, na Alemanha, e "pelo início dos expurgos na Rússia, em 1934", os Manuscritos "causaram profunda e duradoura impressão" em Lukács, Marcuse e Lefebvre. O primeiro, "trabalhando sob a supervisão de Riazanov, em seu exílio em Moscou, em 1931, os decifrando"; o segundo, afirmando com um ensaio de 1932 que "os Manuscritos colocavam toda a teoria do socialismo científico sobre novas bases" e enfatizava "em particular sua visão de que eles demonstravam a importância vital dos fundamentos filosóficos do materialismo histórico em todos os estágios da obra de Marx" e, o último, sendo o responsável pelas primeiras traduções dos Manuscritos.

\footnotetext{
${ }^{7} \mathrm{O}$ autor faz uma distinção entre o tratamento teórico conferido ao Estado no campo filosófico daquele do campo da ciência política, sendo que o último é que orienta a configuração material e institucional do Estado (ANDERSON, 2004).
} 
O desdobramento dos estudos desses autores, mas também de outros marxistas europeus, como Althusser, Gramsci, Della Volpe, dentre outros, eclodiu em recorrentes formulações sobre o Método, causando um afastamento cada vez maior dos "filósofos profissionais" da prática política das massas proletárias (ANDERSON, 2004).

A trajetória do desenvolvimento do próprio Marx foi paradoxalmente invertida pelo marxismo ocidental como um todo. Enquanto, o fundador do materialismo histórico moveu-se progressivamente da filosofia para a política e então para a economia como terreno central de seu pensamento, os herdeiros da tradição que apareceram depois de 1920 gradualmente afastaram-se da economia e da política para se aproximar da filosofia, abandonando o envolvimento direto com aquelas que foram as grandes preocupações do Marx da maturidade, quase tão completamente como este tinha abandonado o exame direto das questões filosóficas que o tinham interessado na juventude [...]. Na verdade, está claro, o que ocorreu não foi, nem poderia ter sido, mera inversão. A empreitada filosófica do próprio Marx estava dirigida, antes de tudo, para um acerto de contas com Hegel e seus mais importantes herdeiros e críticos na Alemanha, especialmente Feuerbach (ANDERSON, 2004, p. 72).

\title{
Outro elemento destacado por Anderson, para a reversão do eixo categorial central
}

de Marx, no marxismo ocidental, foi, de um lado, a experiência real de implantação do socialismo, que levou o debate teórico para endogenia, e, por outro, a influência do stalinismo ${ }^{8}$. Refere:

\begin{abstract}
Com a vitória do "Socialismo em um País" na União Soviética, seguida pela progressiva burocratização do Comintern e pelas perspectivas nacionalistas adotadas pelo comunismo europeu durante e após a Segunda Guerra Mundial, os marcos do debate marxista passaram por uma mudança fundamental. Ocorria agora não apenas uma distância cada vez maior da militância política, mas de qualquer horizonte internacional (ANDERSON, 2004, p.72).
\end{abstract}

\footnotetext{
${ }^{8}$ Nascimento (2007), ao discorrer sobre o contexto histórico em que a obra deste autor foi elaborada, refere polemicamente, nas trilhas do raciocínio de Anderson, que: "Durante mais de vinte anos após o fim da Segunda Guerra Mundial, a produção teórica do marxismo ocidental no campo da teoria política e da teoria econômica foi praticamente inexistente em termos de contribuições originais. Os textos sobre política e economia, que surgiram após a Segunda Guerra Mundial, em sua maioria, eram da lavra dos burocratas dos partidos comunistas e tinham como apanágio a 'esterilidade' teórica, pois não apresentavam nenhuma contribuição decisiva ou original. Tal esterilidade seria tributária de dois elementos. Por um lado, pelo fato de que as discussões sobre a luta de classes e sobre o imperialismo terem sido praticamente monopolizadas pela cúpula dos partidos comunistas (os quais submetiam todas as suas teses à linha oficial do PCUS). Por outro, pela novidade que representava o fenômeno de consolidação de uma dominação burguesa fundada não mais em práticas autocráticas, mas, sobretudo, em práticas democráticas - baseadas na democracia representativa e sufragista. O fenômeno da consolidação em países de capitalismo avançado da democracia burguesa teria escapado às análises de Marx e Lênin e, posteriormente, à tradição que herdara o legado teórico desses autores". (NASCIMENTO, 2007).
} 
Mas, o que o autor de Considerações sobre o Marxismo Ocidental não aborda é que a produção que categoriza como filosófica, em sentido negativo, mesmo sendo produzida em círculos acadêmicos oficiais, isto é, para além das "escolas operárias, do partido, dos movimentos sociais" não foi encastelada pelos muros da academia sem sofrer nenhuma influência da agitação social que ocorria do lado de fora. Justamente, o aprofundamento de questões como as do "método" possibilitaram um novo tipo de relação entre teoria e prática revolucionária, permitindo à teoria lapsos temporais mais longos para sua elaboração e maturação ainda que em contraste com a urgência cotidiana da luta de classes. Além disso, os acontecimentos que levam à adoção da Nova Política Econômica (NEP), após o X Congresso do PCUS, ao assegurar uma série de concessões mercantis na União Soviética, não se furtam da interlocução com intelectuais marxistas de maior envergadura, preocupados com os rumos da Revolução, após a desestabilização do Comunismo de Guerra.

Mesmo nesse contexto, e nisto Anderson é preciso, segundo nossa interpretação, o desenvolvimento de um tipo mais complexo de Estado que acontecia em países como os Estados Unidos, Inglaterra ou Alemanha (ou mesmo a Itália unificada que chamará a atenção de Gramsci) não fora objeto, pelo menos de imediato, de análise do marxismo ocidental. Isto é, o tipo de Estado capitalista necessário à reprodução dos interesses das classes dominantes, que pressupõe a radicalização do trabalho livre - uma de suas características fundantes -, e sustenta-se nos estatutos da democracia burguesa (representação, sufrágio, aparelhos jurídicos-estatais etc.), desestimula a esquerda a produzir teses sobre ele, uma vez que não encontravam referências contundentes sobre o tema em Marx ou em Lênin.

O Estado burguês democrático em si nunca foi objeto de qualquer trabalho importante de Marx, que morreu antes de sua realização, ou de Lênin, cujo inimigo, na Rússia czarista, era um tipo totalmente diferente de Estado. Eram de escala pouco menor, os problemas suscitados pelo rápido avanço da economia capitalista mundial nas duas primeiras décadas após a segunda Guerra, do que as dificuldades existentes no desenvolvimento de uma teoria política capaz de apreender e analisar a natureza e os mecanismos da democracia representativa como uma forma madura de poder burguês (ANDERSON, 2004, p. 72).

Evidentemente que a publicação, em 1917, de O Estado e a Revolução, de Lênin, uma obra capital dentro do marxismo, segundo os dizeres de Florestan Fernandes, marca uma inflexão substantiva nos estudos sobre a problemática teórica e das práticas políticas ao Estado afetas. Mas, são justamente os ventos revolucionários da mudança que fazem com 
que o próprio Lênin se dedique aos assuntos da Revolução abdicando de aprofundamentos posteriores, corroborando a afirmação anterior de Anderson.

Borón (1994, p. 243), por sua vez, refere-se ao desterro e retorno do Estado informando que "o Estado se transformou em um dos eixos principais do debate que atualmente agita as ciências sociais e a vida política das sociedades contemporâneas". O autor atribui esse agito ao advento neoconservador,

[...] que prevalece em todo o mundo e que converteu o Estado em uma espécie de bête noire ${ }^{9}$ que é preciso destruir. Isto não poderia deixar de surpreender 0 estudioso da ciência política, dado que, anteriormente a este esmagador retorno, o conceito de Estado havia sido excomungado da academia e desterrado para os nebulosos territórios da ideologia e do pensamento pré-científico. As razões: uma supostamente incurável vaguidão conceitual e um traço cronicamente formalista o privavam de todo valor heurístico (ANDERSON, 2004, p. 243).

\section{E prossegue:}

Em 1953 - uma época em que, da mesma forma que hoje, também se falava do "fim das ideologias" e do triunfo do capitalismo - David Easton expressava eloquentemente o consenso prevalecente dentre os cientistas sociais de seu tempo ao afirmar que "nem o Estado nem o poder são conceitos que servem ao desenvolvimento da pesquisa política" (ANDERSON, 2004, p. 243).

Como um objeto pulsante para as ciências, até mesmo de um modo geral, isto é, para além das sociais e políticas, como fênix, o Estado ressurge e recupera sua inevitabilidade. Borón (1994, p. 245) lembra a produção latino-americanista que invade a academia norte-americana, tratando de temas como a dependência, o subdesenvolvimento e o Estado, entre os anos 60 e 70 . O regresso virtuoso do Estado como objeto de interesse científico subverte o posicionamento anterior de Easton, que é levado a afirmar que "o Estado agora sitiou o sistema político" e assim, numa tentativa de explicar esse retorno, elenca três principais motivos para o fenômeno: 1 ) o ressurgimento cíclico do marxismo nos Estados Unidos; 2) a persistente necessidade dos conservadores de encontrar alguém a quem possam culpar pela desordem atual das sociedades ocidentais; 3) as recentes tendências em matéria de pesquisa, orientadas para análise de políticas (policy analysis). Borón (1994) considera os argumentos de Easton insuficientes e, por isso, acrescenta a eles: 1) a indubitável estatificação dos processos de acumulação capitalista e da vida cotidiana nas

\footnotetext{
${ }^{9}$ Besta negra (tradução nossa).
} 
sociedades burguesas [...] a partir da recomposição keynesiana posterior à Grande Depressão de 1929; 2) o caráter penetrante e de longa duração da crise política que afeta os Estados contemporâneos, qualquer que seja seu tipo e forma, em todos os seus níveis e, finalmente; 3) a insuportável leveza teórica e a aridez conceitual da ciência política convencional.

Os argumentos de Easton não alcançam os componentes estruturais das relações sociais que engendram à formulação científica. Uma análise mais comprometida com as reais condições em que se autoproduz a crítica, deve levar em conta não apenas os elementos conjunturais, mas também as estruturas em que são gestados. Os diferentes padrões de acumulação capitalista, como bem refere Borón estão na base de qualquer investigação sobre o Estado e as relações de poder. Além disso, ignorar a participação estatal nos processos de reprodução ampliada do capital, com inflexões em toda a vida social, é no mínimo manter-se na superficialidade da análise.

Por isso, esses blecautes nas formulações sobre o Estado, ao longo da história, estão, em nossa opinião, mais condicionados à prevalência do complexo ideológico burguês de determinados tempos, que busca encobrir as contradições engendradas por seu sistema socioeconômico do que necessariamente uma possível irrelevância da temática do Estado como objeto de pesquisa. O Estado nunca abandonou a cena intelectual e política das academias, dos Parlamentos, dos partidos ou das praças públicas. Mesmo quando considerado irrelevante, sua presença na difusão das teses sobre sua própria irrelevância o manteve vivo e afeto ao campo da racionalidade humana.

Assim, entendemos que os fenômenos contemporâneos que dão forma aos novos padrões da acumulação capitalista em escala global, só podem ser entendidos à luz do exame rigoroso das construções racionais da Modernidade - SIM, NÃO É O FIM DA HISTÓRIA - próprias da Filosofia Política, da Ciência Política e da Sociologia e que tem nas relações de poder e o Estado como seu simulacro, eixos centrais da análise.

\section{A luta de classes como apanágio do estado moderno}

As preocupações de grande quantidade de intelectuais em explicar o que é e entender como funciona a sociedade humana (desde o primitivismo até o capitalismo contemporâneo) e nela o Estado, justifica-se, dentre outros motivos, porque intencionam, via de regra, conferir direcionamento político e ideológico ao Estado, seja Ipara destruí-lo, 
após transformá-lo em instrumento para a revolução proletária (Marx, Engels e Lênin), seja para disputá-lo na esteira da "condensação de relações de força" que engendra (Poulantzas) $^{10}$. Essa articulação intencional pode se dar de várias formas: por meio dos partidos políticos, a forma institucional mais utilizada para essas disputas, mas pode ocorrer também por meio e influência das corporações, de agentes públicos ou privados isolados, de organizações sindicais, de movimentos sociais, dentre outros, sempre na direção de corroborar ou refutar grandes ou pequenas construções teóricas que o tiveram como objeto de análise.

É no teor destas construções teórico-metodológicas que os diferentes governos têm encontrado sustentação para colocar em prática seus motins ideológicos, aos quais, alçados ao campo concreto e real da luta de classes, refletem os interesses dos grupos a que se vinculam, transformando-os em ação concreta, ou, em termos pragmáticos, em programas aplicáveis de governo.

Desde o jusnaturalismo de Hobbes, Locke, ou Rousseau, até a incursão contemporânea que leva Blair a seguir os mandamentos da Terceira Via de Giddens, ou mesmo nas articulações de pensamento e ação entre Bresser Pereira e Fernando Henrique Cardoso, em suas ofensivas contrarreformistas no Brasil, intelectuais e estadistas se confundem e se identificam fenomenicamente em processos parasitários de retroalimentação ${ }^{11}$. As defesas pelo fortalecimento ou enfraquecimento, existência ou inexistência do Estado, podem ser dos mais diversos matizes, como dito alhures. Há os que sugerem o fim do Estado como forma de dar vazão à supremacia do mercado e sua mão invisível; há os que defendem o seu fim como a única maneira de proporcionar a efetiva igualdade entre os homens. Outros podem defender sua existência mediante a exacerbação de seu poder regulatório e coercitivo, interferindo nas liberdades individuais, como é o caso

\footnotetext{
${ }^{10}$ A grande questão colocada por Marx, Engels e muitos outros intelectuais da tradição marxista é a "extinção" desse "comitê gestor dos negócios comuns da burguesia". As distinções entre eles, incluindo agora Gramsci, se davam no campo de como encaminhar tal extinção - a luta proletária mesmo - de modo a lograr o êxito revolucionário necessário. Lênin, por exemplo, foi contundente a esse processo quando propõe a "guerra de movimento" e dá outros encaminhamentos em $O$ Estado e a Revolução se aproximando do que Marx argumentou em A Guerra Civil na França. Gramsci, por seu turno, propôs a "guerra de posição" na sociedade civil com a generalização da política pelos aparelhos privados de hegemonia. Um "marxismo" que destoa destes é mesmo o de Poulantzas, que, ao conceber o Estado como "condensação de relação de forças", abre terreno para que se pense em disputas no e pelo Estado.

11 Um exemplo interessante são as observações traçadas por Napoleão Bonaparte e a rainha Cristina da Suécia sobre $O$ Príncipe, de Maquiavel. Há várias edições dessa obra que agregam as notas dos dois estadistas. A que utilizamos é a da Editora Jardim dos Livros (São Paulo, 2007), tradução direta do italiano por Ana Paula Pessoa. Nela, os comentários de Napoleão e rainha Cristina estão incorporados como notas.
} 
dos regimes autocráticos, ao passo que outros podem pensá-lo neutro, diante das disputas próprias da democracia liberal burguesa. Da direita à esquerda, todos têm opinião e posicionamento sobre o Estado. Processo histórico este que o alça dos braços da ciência e filosofia políticas para o campo das teorias do direito, da administração, da administração da produção etc.

O fato é que a definição de Estado nunca será algo acabado, signatário de uma verdade, o que levou Pereira (2008) a afirmar que o Estado, "além de ser um conceito complexo, é um fenômeno histórico e relacional"12.

Desde que jacobinos e girondinos se sentaram em lados opostos na Assembleia Francesa de 1791, a vida de estadistas e estudiosos do Estado tornou-se imbuída da inevitabilidade de sua problematização, ainda que, por vezes, presa ao maniqueísmo do antagonismo político marcado pela vulgarização das noções de direita e esquerda. Desse modo, tanto um polo quanto outro não conseguem precisar, mesmo na polarização que anunciam, uma definição unívoca do Estado; contudo, adicionam elementos que buscam defini-lo ora por suas funções, ora pelas instituições ou corporações que o compõe, ora por sua relação inexorável com a sociedade, ora por todos esses elementos juntos, e assim por diante. Trata-se, então, de entender que o Estado não "existe em abstrato (sem vinculações com a realidade e a história) e nem de forma absoluta (assumindo sempre e para toda vida uma única forma)" (PEREIRA, 2008). Por isso, a natureza do Estado é de imanente problemática. Por problemática, entende-se "o conjunto de perguntas, ideias e suposições que delimitam o terreno no qual se produz determinada teoria, terreno que nem sempre é visível na superfície do discurso teórico, e que, no entanto, determina as condições e as possibilidades de enunciados desse discurso" (BOITO JUNIOR, 2007, p. 42) ou, como referiu Althusser (apud BOITO JUNIOR, 2007, p. 42): “A problemática é a unidade profunda de um pensamento teórico ou ideológico".

Desse modo, Boito Junior (2007) nos lembra que distintas teorias podem ser construídas com base em uma única problemática. Em nosso conjunto argumentativo, a problemática teórico-prática do Estado encontra abrigo numa miríade de teses e teorias que mantém sempre uma base comum, qual seja, a processualidade de sua entificação, o que incide em sua estrutura e nas formas que se materializam ao sabor de distintas conjunturas.

\footnotetext{
${ }^{12}$ Segundo a autora, histórico, porque não existe de forma absoluta e inalterável. É algo em movimento e constante mutação [...] relacional porque não é um fenômeno isolado, fechado ou circunscrito em si mesmo e autossuficiente, mas um fenômeno em relação. (PEREIRA, 2008).
} 
Nos interessa, assim, um tipo particular de Estado, ou seja, o referido a uma formação social específica, historicamente determinada, cujas características lhe dão forma estrutural e que, de modo ainda mais específico, se referencia também as contingências conjunturais. Tratase, pois, daquele tipo de Estado dotado de obrigações positivas que, inevitavelmente, o impelem a exercer regulações sociais por meio de políticas. Ou seja, o Estado em ação (PEREIRA, 2008, p. 99).

É esse tipo de Estado que interessa às análises de conjuntura, pois esse é o tipo que protagoniza impulsos cíclicos voltados ao seu próprio desenvolvimento em atos permanentes de reciprocidade ao desenvolvimento do Modo de Produção Capitalista e que, ao longo dos tempos, tem sido objeto de interesse científico com inflexões diretas nos rumos que as sociedades humanas têm tomado, desde o advento da Modernidade, uma vez que esta tem a luta de classes como seu apanágio.

A luta de classes, desse modo, irá inflexionar toda a preocupação de intelectuais e estadistas em definir e pensar o Estado nas suas mais variadas formas e expressões. Dedutiva ou indutivamente, é possível perceber um fio evolutivo, porém não linear, nas formulações teórico-práticas mais visitadas sobre o tema. Tais formulações expressam, nas ações de seus emissores, as "consciências sociais práticas" dos grupos sociais a que se vinculam ${ }^{13}$.

Marcados pela heterogeneidade, há grupos de formuladores que primam pela explicitação de valores universais, ou por elementos categoriais fundantes que conduzem para análises totalizantes, e, recorrem, sobretudo, às Ciências Sociais ${ }^{14}$. Outros, também com diferenciações internas, nos apresentam de modo mais evidente os valores sensíveis que conformam à problemática do Estado. Estes, por sua vez, dialogam mais fortemente com a filosofia política ${ }^{15}$. Há ainda um terceiro grupo, que se ocupa menos da problemática teórico-prática do Estado (por vezes, até a nega) por entender que as funções a ele afetas se reduzem à participação na busca pelo êxito dos processos que visam administrar as relações

\footnotetext{
${ }^{13}$ Esses intelectuais, mas, sobretudo, os "estadistas", podem ser entendidos como ideólogos de seus grupos sociais. Ideologia aqui tratada não como falsa consciência, conforme nos esclarece Mészáros, quando afirma: "a ideologia não é ilusão nem superstição religiosa de indivíduos mal orientados, mas uma forma específica de consciência social, materialmente ancorada e sustentada. Como tal, é insuperável nas sociedades de classes". (MÉSZÁROS, 2004).

${ }^{14}$ São expoentes dessa perspectiva: Marx (1818-1883); Engels (1820-1895); Lênin (1870-1924); Lukács (18851971); Gramsci (1891-1937); Althusser (1918-1990); Mandel (1923-1995) e Poulantzas (1936-1979); Durkheim (1858-1917); Weber (1864-1920).

${ }^{15}$ Destacam-se: Hobbes (1588-1679); Locke (1632-1704); Kant (1724-1804); Rosseau (1712-1778); Hegel (17701831).
} 
sociais como derivação direta dos mecanismos de gestão das relações de produção. São os que se ancoram fundamentalmente no Direito Positivo e nas teorias gerais da administração dos negócios capitalistas ${ }^{16}$.

De modo geral, todas as perspectivas, por terem invólucro ideológico, apresentam natureza ontológica que se traduz numa espécie de função social, isto é, refletem também não apenas o papel que a ideologia desempenha ante o grupo social de seus portadores como também a conscientização como prévia ideação da prática social de seus agentes. Deste modo, o conjunto de intenções que serão implementadas pelos agentes portadores da ideologia, em termos ontológico-práticos, são encontradas normalmente sob a forma de embate entre liberais e socialistas.

Os primeiros, na sua maioria, se guiam pelos primados da política econômica burguesa, evidenciando, em seus constructos, o liberalismo como valor ético para o tipo de Estado que defendem, ainda que conjunturas históricas específicas possam levá-los a radicalizar ou atenuar as diretrizes liberais, como é o caso do liberalismo radical autocrático ou o social-liberalismo. Já entre os socialistas, podem se destacar tendências, do mesmo modo autocráticas, e outras que, revisando ou reformando as bases de sustentação de suas teses, desembocam em uma heterogeneidade de acepções que vão desde a socialdemocracia até o capitalismo humanizado ${ }^{17}$, sem negar, evidentemente, as posições mais ortodoxas e diferentes das autocráticas.

As fronteiras entre o conhecimento produzido por esses três grupos de formuladores são tênues, por vezes, possibilitando articulações positivas, quando há algum tipo de identificação ético-política ou metodológica; ou negativas, quando se evidenciam contradições inconciliáveis. Contudo, se faz lídimo afirmar que não estamos pondo em confronto filosofias e sociologias, afinal:

\footnotetext{
${ }^{16}$ Os mais visitados nesse campo costumam ser: Adam Smith (1723-1790); Thomas Malthus (1766-1834); David Ricardo (1772-1823); Fayol (1841-1925); Hayek (1849-1992); Taylor (1856-1915); Henry Ford (1863-1947); F. Mises (1881-1883); Keynes (1883-1946); e Friedman (1912-2006).

${ }^{17} \mathrm{O}$ "revisionismo", como ficou conhecido o movimento protagonizado por Bernstein e Kaustky, sobretudo a partir da II Internacional, propunha a revisão dos escritos de Marx subtraindo deles a perspectiva de uma irrupção violenta e revolucionária como meio de superação do capitalismo. Sem dúvida, são os teóricos mais importantes da gênese da social-democracia. As teses sobre o capitalismo humanizado, embora tenham bases clássicas, estão em voga na pós-modernidade, inclusive em grande parte dos chamados novos movimentos sociais. Ver, nesse sentido, de Boaventura de Sousa Santos (2005, 2006, 2007a, 2007b, 2007c, 2008).
} 
[...] em um ensaio, Le philosophe et La sociologie, Merleau-Ponty assinalava os riscos de uma rivalidade cultivada entre filósofos e sociólogos, os primeiros considerando-se possuidores da verdade porque detentores da Ideia, os segundos reivindicando para si a posse do verdadeiro porque conhecedores do Fato. É uma rivalidade obscurantista que priva o filósofo de contato com o mundo e o sociólogo, da interpretação do sentido de sua investigação; tal atitude esconde algo típico da ideologia: a crença na existência do Sujeito do Conhecimento como olhar separado que sobrevoa imaginariamente o real e o domina através de um sistema de representações, sem que seja preciso indagar qual o sentido dos fatos nem qual a necessidade das ideias ao serem realizadas pela experiência. (CHAUÍ, 2007, p. 104).

Evidencia-se, portanto, a relevância do pensamento construído pelos intelectuais que considera-se significativos para esta análise - também por serem referências recorrentes no Serviço Social - , pois, na sua maioria, inauguram escolas de pensamento que influenciam até os dias atuais, à direita, à esquerda; na porosidade do centro ou em suas frações.

Das relações de poder (e sua manutenção) em Maquiavel até condensar correlações de forças típicas da vida social, em Poulantzas, a problemática do Estado foi se metamorfoseando, de cérebro em cérebro, até chegar aos elementos que nos permitem hoje elencar categorias teóricas para a análise de suas diferentes nuanças conceituais, teóricas, políticas, metodológicas e éticas.

Quando analisamos o Estado conferimos um destaque especial para as "narrativas" no campo da tradição marxista, tanto por sua diversidade quanto pela abrangência, mas, sobretudo, porque é nesse campo que residem os nexos ontológicos da crítica que empreendemos conforme já dialogado na Introdução.

Ademais, a variedade de perspectivas no bojo dessa tradição tende a mostrar a fecundidade da problemática do Estado nesse campo de construção do conhecimento, mantida a unidade interna com relação ao modo como os diferentes autores evoluíram a sínteses diferenciadas partindo do mesmo tema, isto é, seus caminhos metodológicos coincidem nas preocupações que circunscrevem as análises da configuração e do desenvolvimento do Estado burguês, ou Estado capitalista ${ }^{18}$. Deste modo, a presença das classes sociais e da processualidade das relações de produção e reprodução social é constante, nos autores marxistas, conquanto se tratar de categorias centrais, na obra de

\footnotetext{
18 Utilizou-se sem distinção os termos "Estado capitalista" e "Estado burguês" entendendo a burguesia como a classe que emerge como dominante no tipo capitalista de Estado, apresentando vinculação orgânica entre si.
} 
Marx. Não por acaso, neste grupo, encontra-se estadistas revolucionários, como Lênin ou Trotski.

Não se está assim, como já destacado, apurando teorias do Estado contidas nas formulações dos intelectuais que foi anteriormente convocado, se está explicitando a construção e evolução de um pensar crítico sobre o Estado, que inter-relaciona a normatividade e operatividade como meio embrionário para uma contribuição ao estudo sobre o Estado na contemporaneidade, e os modos como nos relacionamos com tais estudos (e práticas) ao longo do nosso cotidiano enquanto classe trabalhadora.

\section{Conclusão}

De todos os campos da teoria social, o campo que se filia à tradição marxista, sem dúvida, é um dos mais fecundos em debates, quase sempre acalorados, sobre aspectos específicos ou gerais dos fenômenos sociais a que os intelectuais se propõem a analisar. $\mathrm{Na}$ década de 1950, ocorreu o conhecido debate internacional sobre a transição do feudalismo para o capitalismo, em que tomaram parte Paul Sweezy, Maurice Dobb, H. K. Takahashi, Christopher Hill, Georges Lefebvre, A. Soboul e Giuliano Procacci. Divergiam, fundamentalmente, sobre os condicionantes essenciais da transição que levara ao fim gradativo e processual do modo feudal de organização da produção. O ponto de convergência entre eles está no fato de admitirem que o capitalismo revoluciona não apenas as características fundamentais dos modos de produção que o antecedem, como também se faz acompanhar de um padrão de sociabilidade que se difunde de modo ágil. Portanto, ainda que não haja consenso sobre a "certidão de nascimento" do capitalismo, é inegável que, desde que esse modo de produção se torna dominante, não abandona mais suas inerentes estratégias de legitimação. Essas estratégias ganham espaço de formulação e são disseminadas na instituição dos Estados burgueses.

No capitalismo tardio, em sua feição monopólica, as características genéricas ganham ainda mais força e tornam naturais para as massas, pela dominação que exercem a burguesia e o Estado burguês, suas crises cíclicas alternadas pelos períodos de ondas longas expansivas, como demonstrara Mandel.

No período entre guerras, nos países de capitalismo avançado, a difusão desse modo de produção consolidou Estados sob o signo da democracia liberal de massas. Essa combinação entre a base material de sustentação do capital com o tipo de Estado que a 
legitima vem sendo propalada como o último estágio possível de desenvolvimento da história humana. No Brasil, desde os anos 1970 esse processo ideopolítico toma fôlego e se naturaliza não apenas no reformismo e contrarreformismo como também nas características particulares do desenvolvimento capitalista brasileiro como o patrimonialismo, o clientelismo, o fisiologismo político, o mandonismo local, dentre outras expressões do poder de classe burguês difundidas pela ação estatal.

Alvo de estudos, por parte de intelectuais dos mais variados campos do conhecimento, a democracia liberal de massas, expressão política de um tipo particular de Estado burguês, tem ressaltado, em algumas produções, aquilo que parte dos autores identifica como sendo suas benesses. Por vezes, ignoram seus limites civilizatórios, quando não muito caem na armadilha do fim da história ou se rendem ao institucionalismo. Parte dessa guinada à direita deve-se - pelo menos no entendimento de nossa argumentação - ao abandono gradual de problematizações totalizadoras acerca do Estado capitalista tanto na ciência política quanto na prática política como vimos em Perry Anderson e em Atílio Borón. Mas, não se entende esse abandono como um esvaziamento completo.

Se é correto perceber que se abre tal lacuna, também pode ser correto observar que as tendências do conhecimento pós-moderno preenchem o vazio com incursões sobre aspectos particulares, imediatos e efêmeros sobre a democracia liberal e seus componentes constituintes e o Estado que os reveste. De um lado, nota-se uma adesão ao pragmatismo do funcionamento da máquina estatal, de modo a despolitizar o Estado e as relações sociais a ele inerentes, a exemplo das produções de Bresser Pereira sobre reforma do Estado quando ministro do Presidente FHC, por outro lado, voltam-se as atenções à supremacia do mercado, isentando-o, falaciosamente, de relações com o Estado, tanto por parte dos liberais defensores do laissez-faire quanto dos críticos da mão invisível, sustentando as construções teóricas pós-modernas, como dissemos.

Contudo, para nós, é no interior do Estado e da sociedade civil - aqueles que para Lukács são os dois complexos sociais fundamentais, em relação - que se evidenciam as sínteses da dinâmica social com precisão. Para Mészáros (1993), é no Estado “onde a superestrutura política e jurídica na rede de inter-relações dialéticas entre a base material de uma determinada sociedade e suas várias instituições e formas de consciência são localizadas". E tais formas não são alheias ao jogo que se estabelece entre as classes. Ao contrário. Poulantzas afirma que as classes consubstanciam no Estado uma condensação de 
relação de forças que condicionam a relação com a sociedade por meio do complexo produtivo (relações de produção), às instituições, à política e à ideologia.

Desse modo, as análises, na perspectiva da totalidade social, são fundamentais para se entender o Estado e, com isso, compreender a sociedade e suas formas políticas e ideológicas de organização, como, por exemplo, a democracia liberal de massas. É nesse sentido que lanni $(1989$, p. 7) afirma:

A análise do Estado é uma forma de conhecer a sociedade. Se é verdade que a sociedade funda o Estado, também é inegável que o Estado é constitutivo daquela. As forças sociais que predominam na sociedade, em dada época, podem não só influenciar a organização do Estado como incutir-Ihe tendências que influenciam o jogo das forças sociais e o conjunto da sociedade.

É nesse caminho que os Estados contemporâneos se instituíram em suas características fundamentais, após a insurreição de 1789, resguardadas suas particularidades históricas (econômicas, políticas, culturais, ideológicas etc.), e que vem provocando mudanças nas estruturas dos Estados burgueses até os dias atuais, e que nos serve para ratificar a construção marxista que o aponta como transitório. Transitório na perspectiva da conquista de uma ordem societária alternativa à ordem do capital, mas permanente, caso se faça referência aos padrões burgueses que preconizam o desenvolvimento de suas sociedades de mercado. Deste modo, assim como o MPC, desenvolver-se é parte e condição de existência do Estado burguês.

É, pois, esse desenvolvimento que permitirá exercer a crítica sobre o Estado e com isso avançar no projeto que estabelece uma ordem alternativa a ordem do Capital.

\section{Referências}

ANDERSON, P. Considerações sobre o marxismo ocidental nas trilhas do materialismo histórico. São Paulo: Boitempo Editorial, 2004.

BOBBIO, N. Dicionário de política. 13. ed. Brasília: UnB, 2007.

BOITO JUNIOR, A. Estado, política e classes sociais: ensaios teóricos e históricos. São Paulo: Unesp, 2007.

BORON, A. Estado, capitalismo e democracia na américa latina. Rio de Janeiro: Paz e Terra, 1994.

CHAUÍ, M. Convite à filosofia. 14. ed. São Paulo: Ática, 2010. 
CHAUÍ, M. Cultura e democracia: o discurso competente e outras falas. 12. ed., São Paulo: Cortez, 2007.

CODATO, A. Poulantzas, o estado e a revolução. Revista Crítica Marxista, Campinas, SP, n. 27, p. 65-85, 2008.

IANNI, O. Estado e capitalismo. 2. ed. São Paulo: Brasiliense, 1989.

MARCUSE, H. Razão e revolução: Hegel e o advento da teoria social. São Paulo: Paz e Terra, 2004.

MÉSZÁROS, I. Filosofia, ideologia e ciência social: ensaios de negação e afirmação. São Paulo: Ensaio, 1993.

MÉSZÁROS, I. O poder da ideologia. São Paulo: Boitempo Editorial, 2004.

NASCIMENTO, A. O Estado capitalista na análise de Nicos Poulantzas. Revista Palavra Mundo, Campinas, SP, v. 1, n. 1, 2007.

PAULA, R. F. S. Estado capitalista e serviço social: o neodesenvolvimentismo em questão.

Campinas: Papel Social, 2016.

PEREIRA, P. A. P. Política social: temas \& questões. São Paulo: Cortez, 2008.

SANTOS, Boaventura de Sousa. A gramática do tempo: para uma nova cultura política. Porto: Afrontamento, 2006.

SANTOS, B. S. A gramática do tempo: para uma nova cultura política. 2. ed. Porto: Afrontamento, 2008.

SANTOS, B. S. O fórum social mundial: manual de uso. São Paulo: Cortez, 2005.

SANTOS, B. S. Para uma revolução democrática da justiça. São Paulo: Cortez, 2007a.

SANTOS, B. S. Poderá o direito ser emancipatório? Vitória: Faculdade de Direito e Fundação Boiteux, 2007b.

SANTOS, B. S. Renovar a teoria crítica e reinventar a emancipação social. São Paulo: Boitempo Editorial, 2007c.

SOUZA, N. R. Sociologia política. Curitiba: IESDE Brasil, 2008. 
Recebido em: 15/09/2018 Aceito em: 17/10/2018 